\section{Local Treatment of Experimental Pyocyaneus Ulcers of the Cornea with Albucid Soluble}

$J_{0 x}{ }^{1}$ recently demonstrated that the development of experimentally produced ulcers of the cornea in rabbits could be favourably influenced by the parenteral administration of sodium sulphapyridine. It has also been shown that sulphanilamide penetrates freely through the cornea ${ }^{2,3}$.

We have investigated the effect of local application of a water-soluble sulphonamide on experimental ulcers in seventeen rabbits. In each animal a definite area in both eyes was denuded of epithelium by means of a discission needle. Great precautions were taken to ensure that the lesions were equal in both eyes. A 24-hour culture of $B$. pyocyaneus (kindly supplied to us by Dr. Oag, of the Department of Bacteriology of the University of Edinburgh) was then applied to these denuded areas by means of a metal loop; the same strain of $B$. pyocyaneus was used throughout all the experiments.

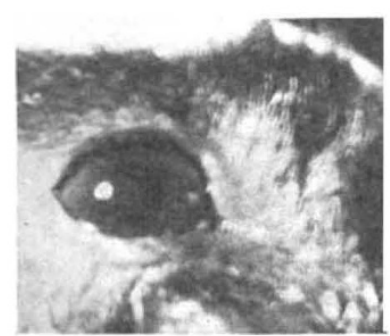

(a)

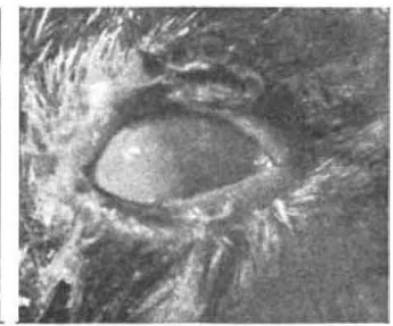

(b)
Fig. 1.

SHOWING THE CONDITION OF THE CORNEA IN THE TREATED (a) AND CONTROL $(b)$ EXES OF A RABBIT ON THE THIRD DAY AFTER THE PRODUCTION OF THE LESION.

Treated eye: cornea healed and showing only a small superficial scar situated at the centre of the cornea immediately adjacent to the light-reflex which is overlying the margin of the pupil. Control eye : severe abscess involving half the cornea.

One hour after the application of the culture several drops of a 30 per cent solution of albucid soluble (which forms a neutral solution) were applied to the cornea of one eye in each animal, the other eye being used as a control and receiving several drops of saline. This treatment was continued four times a day until the lesions were quiescent.

In the majority of the 'control' eyes extensive ulceration occurred and a complete or partial 'ring abscess' developed, the end result being either perforation or gross scarring of the cornea with extensive pannus formation. In some animals, however, the ulceration was limited to the site of scarification, and the resultant scar was very little larger than the original lesion.

In every animal the lesion in the control eye was more severe than that of the treated eye. In eleven animals the difference was very marked (see accompanying illustration), in four animals the difference was less marked, but the treated eye was still definitely better than the control, while in two rabbits the treated eye was only slightly better.

The extent to which ulceration or abscess formation occurred in the cornea is summarized in Table 1.
It is noteworthy that a partial or complete ring abscess developed in twelve of the control and in only three of the treated eyes. Hypopyon was observed in five of the control eyes and in only one of the treated eyes.

\begin{tabular}{|c|c|c|c|}
\hline & $\begin{array}{c}\text { No } \\
\text { ulceration. }\end{array}$ & $\begin{array}{l}\text { Ulceration } \\
\text { present but not } \\
\text { extensive. }\end{array}$ & $\begin{array}{l}\text { Extensive ulcer- } \\
\text { ation, abscess } \\
\text { formation, or } \\
\text { necrosis, with or } \\
\text { without perfora- } \\
\text { tion. }\end{array}$ \\
\hline Control eyes & 0 & 4 & 13 \\
\hline Treated eyes & 11 & 4 & 2 \\
\hline
\end{tabular}

Conjunctivitis did not play a prominent part in the lesions produced, but again the treated eyes were on the whole very definitely better than the controls, and in no case was the treated eye worse than the control eye of the same animal. The results are shown in Table 2.

\begin{tabular}{crccc} 
& \multicolumn{4}{c}{ Table 2 } \\
& Nonjunctivitis & & \\
Control eyes & 0 & Slight & Moderate & Severe \\
Treated eyes & 10 & 10 & 6 & 1 \\
& & 6 & 0 & 1
\end{tabular}

The expenses of this investigation have been defrayed by the W. H. Ross Foundation for the Prevention of Blindness. We are greatly indebted to Mr. Edwards, of Messrs. Schering, London, for the supply of ampoules of 30 per cent solution of albueid soluble.

Department of Pharmacology,

J. M. RoBson.

G. I. SCOTT

University of Edinburgh. July 14.

${ }^{1}$ Joy, H. H., Proc. Soc. Exp. Biol., 45, 709 (1940).

2 Luo, T. H., and P'an, S. Y., Chinese Med. J., 58, 167 (1940).

${ }^{3}$ P'an, S. Y., Proc. Soc. Exp. Biol., 46, 31 (1941).

\section{Sulphanilylbenzamide in the Chemo- therapy of Bacillary Dysentery}

SULPHANILYLGUANIDINE, first described in $1938^{1}$, was recently introduced by Marshall and his colleagues $^{2}$ in the treatment of bacterial infections of the intestinal tract. A subsequent report ${ }^{3}$ dealt with the successful trials of this compound in acute bacillary dysentery due to Flexner and Sonne types in children. The use of the drug is based on its potent antibacterial properties, its solubility in water and its poor absorption from the gut. We have reexamined a large number of drugs of the sulphanilamide and sulphone classes having similar characteristics and have found two soluble compounds, 4: $4^{\prime}$-bis- $\gamma$-phenyl- $n$-propylaminodiphenylsulphone tetrasodium sulphonate and sulphanilylbenzamide to be more effective in vitro than sulphanilylguanidine. However, when these compounds were incorporated in the diet of mice, only sulphanilylbenzamide was as efficient as sulphanilylguanidine in its antibacterial action on the coliform organisms of the gut. When fed to rabbits by stomach tube, sulphanilylbenzamide is poorly absorbed, but it is absorbed to the extent of one and a half times that of sulphanilylguanidine.

Our in vitro tests compared the antibacterial activity of constant drug concentrations in a stock broth against graded inocula of selected intestinal 